\title{
"Uma estória de amor" e O último voo do flamingo: literatura e ambientalismo em Guimarães Rosa e Mia Couto
}

\author{
Teresinha Gema Lins Brandão Chaves ${ }^{1}$
}

RESUMO: Este artigo é um estudo comparado do conto "Uma estória de amor (Festa de Manuelzão)", de Guimarães Rosa e o romance $O$ último voo do flamingo, de Mia Couto, centrado na relação homem e meio ambiente.

ABSTRACT: This article is a comparative study of the short story "Uma estoria de amor", by Guimarães Rosa, and the novel O último voo do flamingo, by Mia Couto. The analyses will be centered on the mankind and the environment.

PALAVRAS-CHAVE: Ecocrítica; Guimarães Rosa; Mia Couto.

KEYWORDS: Ecocriticism; Guimarães Rosa; Mia Couto.

Disse também Deus: Produzam as águas animais viventes, que nadem nas águas; e aves, que voem sobre a terra, e debaixo do firmamento do céu. [...] E viu Deus que isto era bom.

(Gen. 1, 20-21)

O Gênesis, primeira narrativa poética das Escrituras, conta a história da origem do mundo. Durante seis dias, Deus, criador do céu, da terra e de todos os seus ornatos, com sua palavra onipotente, produziu e estabeleceu plenitude e ordem num universo, no princípio, caótico. Assim, seguindo uma ordem determinada, realizou seu trabalho de criação: no primeiro dia, preparou a região sidérea; no segundo, a atmosférica e no terceiro a terrestre. Nos três dias seguintes, colocou sobre cada uma das partes, os seus respectivos habitantes: no

\footnotetext{
${ }^{1}$ Doutoranda em Estudos Comparados de Literaturas de Língua Portuguesa, FFLCHUSP. Pesquisa: A complexidade ambiental em Guimarães Rosa e em diários de viajantes portugueses.
} 
"dia quarto", os astros na sidérea; no "dia quinto", aves e peixes na atmosférica e no "dia sexto", os animais e o homem, na terrestre. No sétimo dia, descansou. ${ }^{2}$

O Homem no Paraiso, narrativa seguinte, descreve um mundo em que todas as plantas do campo, as ervas da terra, todas as “castas de árvores agradáveis à vista, e cujo fruto era gostoso ao paladar" (Gen. 2, 9) brotavam da terra, regadas por rios e fontes. Ao homem foi confiado o "hortar e guardar" (Gen. 2, 15).

Como único ser semelhante a Deus, caberia, ao homem, reinar sobre o planeta, mantendo viva a consciência de que "a terra lhe foi concedida para usufruto e não para consumo ou degradação" (MARSH, 1864, apud DIEGUES, 2001, p. 30); de que a modificação da natureza é benéfica até o ponto em que não interfere drasticamente no ecossistema como um todo e de que tudo na natureza tem seus limites, inclusive o progresso humano (KRUTCH, 1958, apud DIEGUES, 2001, p. 33). No entanto, a história e a literatura mostram que os modos de apreensão do mundo natural, pelos homens, vêm comprometendo cada vez mais a vida no planeta.

No que concerne à literatura, o seu caráter de conferir às palavras mais do que meros instrumentos de saber, mas "projeções, explosões, vibrações, maquinarias, sabores" (BARTHES, 1989, p. 39) e, mesmo que, com breve fulgor, ser capaz de conferir visibilidade ao real, faculta aos escritores a prerrogativa de restaurar alianças e valores. É o que observamos, por exemplo, no conto "Uma estória de amor (Festa de Manuelzão)", do livro Manuelzão e Miguilim, de Guimarães Rosa (1984) e no romance $O$ último voo do flamingo, de Mia Couto (2005). Neles, a natureza se faz presente e adquire uma pluralidade de significados, dá visibilidade ao real e a outra dimensão do "habitar o mundo". Na Samarra, cenário de Rosa, "dava alegria a gente ver o regato botar espuma e oferecer suas claras friagens, e a gente pensar no que era o valor daquilo" (p. 155). Em Tizangara, paisagem literária de Mia Couto,

${ }^{2}$ Cf. comentários do Gênesis, Bíblia Sagrada, Encyclopaedia Britannica Publishers, 1972, p. I, 2. 
em fins de tarde, os flamingos "empurravam o sol para que o dia chegasse ao outro lado do mundo" (p. 47).

É o regato espumoso e frio da narrativa de Rosa, sobre o qual o personagem enigmático "velho Camilo" vai contar a estória, bem como os flamingos, "tragados por longinquas trevas", sobre os quais, no romance de Mia Couto, o também enigmático "velho Sulplício" vai contar, ao filho, a estória, que merecem atenção. Em Guimarães Rosa, o "velho Camilo" conhecia o segredo do riacho seco. Por sua vez, em $O$ último voo do flamingo, o "velho Sulplicio" aprendia a língua dos pássaros e guardava "inesqueciveis palavras" sobre a carga de crueldade usada, pelos homens, na caça às aves.

No que se refere à relação homem e natureza, Enrique Leff observa que "o ambiente não é a ecologia, mas a complexidade do mundo". Para o educador, o saber ambiental "ultrapassa o campo do logos científico e abre um diálogo de saberes onde se confrontam diversas racionalidades e tradições" (LEFF, 2002, p. 19). Nessa abertura, ele postula a construção de um saber ambiental centrado no pensamento e no ser, no encontro de identidades, no questionamento da historicidade da verdade, na utopia e na articulação das ciências com as diferentes significações culturais designadas à natureza. E traça o caminho para se repensar a racionalidade ambiental, a partir "do ser na cultura dos diferentes contextos nos quais codifica e significa a natureza, reconfigura suas identidades e frágua seus mundos de vida" (Ibid.).

Nesse sentido abre-se o caminho para uma reflexão da complexidade ambiental, a partir dos elementos "água” e "pássaro" de "Uma estória de amor" e O último voo do flamingo, através dos quais, Guimarães Rosa e Mia Couto, pela palavra, resgatam a concepção de natureza viva, móvel e constituída de significados.

\section{"Uma estória de amor"}


Se, para Guimarães Rosa, "a literatura só pode nascer da vida" e "tem de ser a voz do compromisso do coração" (LORENZ, 1994, p. 48), o apelo da natureza, ante a sua degradação e extinção, marca a sua obra. A percepção sinestésica do mundo natural através de imagens, cores, luzes, cheiros e sons; as descrições precisas de inúmeros animais, vegetais, das condições de tempo e do relevo mostram o lado naturalista do escritor.

Entre os elementos da natureza presentes em sua obra, os rios têm um papel de destaque, para ele, referência significativa e sedutora, conforme confessaria ao entrevistador:

Gostaria de ser um crocodilo, porque amo os grandes rios, pois são profundos como a alma do homem. Na superficie são muito vivazes e claros, mas nas profundezas são tranqüilos e escuros como os sofrimentos dos homens. Amo ainda mais uma coisa de nossos grandes rios: a eternidade. Sim, rio é uma palavra mágica para conjugar eternidade (LORENZ, 1994, p.37).

Em "Uma estória de amor", ao lado da estória da festa de inauguração da Capela da Samarra, o episódio "do riachinho xexe e, puro, ensombrado, determinado no fino, com regojeio e suazinha algazarra" (ROSA, p. 155), do qual não se economizava água para se beber e quando menos se esperava "cessou", se constitui num enigma.

Ao problematizar dois momentos vitais da lei da natureza sobre as águas, dos quais já não podemos escapar (escassez e excesso), Guimarães Rosa imprime na ordem cultural, embora codificado em forma de parábola, um alerta sobre as frequentes interferências do homem sobre o ciclo hidrológico. Na Samarra aconteceu, por conta de um erro. "E de quem tinha sido o erro? Mas que podia acontecer a qualquer um mestre de mais sertão, pessoa perita nas solidões e tudo" (Ibid.), afirma Manuelzão. E continua:

Porque, dantes, se solambendo por uma grota, um riachinho descia também a encosta, um fluviol, cocegando de pressas, para ir cair, bem embaixo, no Córrego das Pedras, que acabava no rio de-Janeiro, que mais adiante fazia barra no São Francisco. Dava alegria, a gente ver o regato botar espuma e oferecer suas claras 
friagens, e a gente pensar no que era o valor daquilo. [...] Então deduziram de fazer a Casa ali, traçando de se ajustar com a beira dele, num encosto fácil, com piso de lajes, a porta-da-cozinha, a bom de tudo que se carecia. Porém, estrito ao cabo de um ano de lá se estar, e quando menos se esperassem, o riachinho secou (Ibid.).

Maria Luiza Ramos lembra que "[q]uando um rio encontra obstáculo o seu curso se desvia, assim como o ramo se torce junto à pedra, o vento reflui ao se chocar na montanha" (2000, p. 65). Para a autora, o impulso é intrínseco, seja o elemento a água, a seiva, seja o ar, enquanto o obstáculo é extrínseco, está ali, na sua alteridade interposta no caminho. Na complexidade da relação homem e natureza, o obstáculo não se encontra apenas fora, mas se torna também intrínseco ao sujeito. Assim, o desvio das águas do riacho processa em Manuelzão um deslocamento de seu universo interior:

Foi no meio duma noite, indo para a madrugada, todos estavam dormindo. Mas cada um sentiu, de repente, no coração, o estalo do silenciosinho que ele fez, a pontuda falta da toada, do barulhinho. [...] Aî, todos se levantaram, caçaram o quintal, saíram com luz, para espiar o que não havia [...]. Triste duma certeza: cada vez mais fundo, mais longe nos silêncios, ele tinha ido s'embora, o riachinho de todos. [...] E o que a tocha na mão de Manuelzão mais alumiou: que todos tremiam água nos olhos. Ainda esperaram ali, sem sensatez; por fim se avistou no céu a estrela-d'alva. O riacho soluço se estancara, sem resto, e talvez para sempre. Secara-se a lagrimal, sua boquinha serrana. Era como se um menino sozinho tivesse morrido (ROSA, p.156).

A ausência do "riachinho" passa a ocupar, ao longo da narrativa, o pensamento de Manuelzão. Num primeiro momento, teme como presságio de morte, apesar de não querer "suspeitar em sua natureza própria um anúncio de desando, o desmancho, o ferro do corpo" (Ibid.). "Pensou que estivesse com mau-olho" (Ibid.). Por outro lado, a ordem social, inerente ao sujeito, introjeta em Manuelzão, algo a ser decifrado. "Mas tudo vem de mais longe" (Ibid.), ele se lembrava. E no fim, “as coisas se emendavam” (Ibid.). E, agora, "toda manhã, cada por dia, o Chico Carreiro atrelava suas quatro juntas de bois, e desciam até às Pedras, o carro cheio de latas, para buscar a água do usável. 
Sempre as crianças o acompanhavam; e às vezes o velho Camilo" ( p. $157)$.

É o velho Camilo, personagem enigmático, quem conhece o Romanço do Boi Bonito. Contrapondo-se ao riachinho silenciado e seco, a parábola do boi evoca a natureza em seu estado primeiro, intocada pela mão do homem e sua fúria por produção e dominação. $\mathrm{Na}$ narrativa do velho Camilo há algo a ser decifrado: a natureza como mestra e como medida, para se aprender o que funciona, o que é apropriado e o que é durável. Com voz "singular" contou a estória do "Boi Bonito". Até que, chegado ao clímax:

Num campo de muitas águas. Os buritis faziam alteza, com suas vassouras de flores. Só um capim de vereda, que doidava de ser verde - verde, verde, verdeal. Sob oculto, nesses verdes, um riachinho se explicava: com a água ciririca - "Sou riacho que nunca seca..." - de verdade, não secava. Aquele riachinho residia tudo. Lugar aquele não tinha pedacinhos (p. 253-254).

Naquele lugar o boi cantava "claro e lindo". E o velho Camilo repetia o canto. Cantiga que, conforme o narrador, "devia de ser simples, mas para os pássaros, as árvores, as terras, as águas” (p. 255), porque a natureza é sábia. Na Samarra, o riachinho secou. Teria sido desviado de seu caminho? Manuelzão acreditava que "tudo vem de mais longe". Por fim, pensou:

Restavam as duas filas de pequenas árvores, se trançando por cima da deixa do riacho, formando escuro um tubo fundo, onde as porcas iam parir seus leitões e as guinés punham ovos. Não se podia derrubar aquela linha de mato, porque, um dia quem sabe, o riachinho podia voltar, sua vala ficava à espera, protegida ( $\mathrm{p}$. 157).

Com relação à transposição de águas, estudos comprovam que além de alterar o padrão espacial de vazão natural, o desvio pode causar catástrofes como ocorreu com o Mar de Aral, no Cazaquistão. Esse megaprojeto de transposição das águas de dois rios, visando à expansão econômica sem considerar os efeitos posteriores, criou na Ásia, pela ação humana, um novo deserto, afetando não só os recursos 
hídricos de vasta região, mas um conjunto complexo de economias regionais e condições sociais (TUNDISI, 2003, p. 46-47).

O que esperar da polêmica transposição do Rio São Francisco? Megaprojetos produzem megaimpactos que podem vir de regiões muito distantes e não necessariamente das margens de rios ou lagos. $\mathrm{O}$ "velho Camilo" sabia disso. Só "não sabia dizer, sabia dentro das ignorâncias" (ROSA, p. 240).

O Programa das Nações Unidas para o Meio Ambiente (PNUMA), numa avaliação sobre os problemas mundiais de água e a degradação dos recursos hídricos do planeta, identificou oitenta países com sérias dificuldades para manter a disponibilidade de água (quarenta por cento da população mundial). Concluiu-se, ainda, que mais de vinte por cento das reservas de água doce estão ameaçadas ou em perigo em razão da construção de barragens, danos causados por poluição, contaminação e mudanças climáticas globais. Estima-se que trinta a sessenta milhões de pessoas foram deslocadas diretamente pela construção de represas em todo o planeta (TUNDISI, 2003, p. 42-43).

Em "Uma estória de amor", com a parábola do riacho seco, Rosa vai sustentar valores que não aspiram a alcançar um status de cientificidade, mas a promover "um diálogo entre ciência e saber, tradição e modernidade" (LEFF, 2002, p. 169). Diálogo que implica a revalorização do conhecimento do homem sertanejo e de suas práticas culturais produzidas em harmonia com o mundo natural.

\section{O último voo do flamingo}

"Aquele a quem a Natureza começa a desvendar seu segredo manifesto experimenta um anseio irresistivel por sua intérprete mais digna: a Arte", afirmou Goethe, para quem "as leis que o artista segue não são outras senão as leis eternas da Natureza, no entanto puras e não influenciadas por qualquer obstrução". Para o espírito criador "não importa o que é; e sim o que poderia ser; não o real, e sim o possivel" (GOETHE apud STEINER, 1998, p. 29-30). 
No romance de Mia Couto, O último voo do flamingo, a arte nos conduz a uma elevação perante o mundo real, ao apresentar, de forma ficcional, a evolução natural de Moçambique, após sua Independência. Ao lado da estória dos soldados de paz da ONU, que explodiam misteriosamente, as "leis eternas da Natureza" se manifestam em Tizangara, que se desdobrava em três: Tizangara-terra, Tizangara-água, Tizangara-céu.

Tizangara-terra "foi engolida pelo mato". Segundo o narrador, "a cidade foi sendo tão abandonada que até as coisas foram perdendo seus nomes. [...], por exemplo: aquilo se chamava casa. Agora, com raízes preenchendo as paredes em ruínas, mais lhe competia o nome de árvore" (COUTO, p.67).

$\mathrm{Na}$ velha casa de Sulplício, sob a sombra do tamarindo, o narrador se deixa afogar em lembranças:

Minha infância fazia ninho nessa árvore. Em minhas tardes de menino, eu subia ao último ramo como se em ombro de gigante e ficava cego para assuntos terrenos. Contemplava era o que no céu se cultiva: plantação de nuvem, rabisco de pássaro. E via os flamingos, setas rapidando-se furtivas pelos céus (p. 159).

Comum às mitologias, a "árvore cósmica"3 é atualizada, em um "soberano tamarindo", no contexto da velha casa da vila de Tizangara. $\mathrm{Na}$ sua sombra, o narrador condensa o passado e o presente e convoca saudades como "a enevoada memória da criança escondendo o brinquedo entre as raizes do tamarindo" ( p.161-162).

Mas agora em Tizangara, no lugar de brinquedos enterravam-se minas, no lugar de árvores, cultivavam-se guerras. Até "nos matos onde ninguém nunca se apessoara" (p. 109) ainda tinha "o pé da guerra". "A pegada está viva" (p.112), a mãe lhe dissera, às margens da floresta.

\footnotetext{
${ }^{3}$ Segundo RAMOS, "a árvore é considerada o símbolo cósmico por excelência, pelo fato de que os três niveis cósmicos - o subterrâneo, o terrestre e o aéreo - se encontram nela reunidos, desde as raízes que mergulham na terra, até o tronco, que nela repousa, e os galhos e folhas, que habitam o ar" (2000, p.77).
} 
Em Tizangara-água, "os estranhos filhos dos antepassados" sonham com o "último lugar do mundo", que tinha sido o "primeiro local da vida":

À minha volta tudo era água, transbordação de todos os rios. O morro era a única ilha em todo o horizonte. [...] Nossa casa era um barco amarrado em nosso destino. [...] Agora, dezenas de anos depois, eu me sentava, solitário sobrevivente, nesse último resto de mundo. Passava por mim, na força da correnteza, chifre de boi, tronco de chanfuta, tecto de palhota. Os restos de tudo, como se a terra inteira tivesse naufragado. Como se o rio Madzimadzi fosse o mar todo em desaguação (p.206-208).

Mas é em Tizangara-céu, onde os flamingos alçavam voo, em fins de tarde, que Mia Couto, encontra na palavra "o mágico reinício de tudo", levando consigo quem consegue aprofundar-se em sua obra. Segundo o narrador:

Minha mãe ficava calada, contemplando o voo. Enquanto não se extinguissem os longos pássaros ela não pronunciava palavra. Nem eu me podia mexer. Tudo, nesse momento, era sagrado. Já no desfalecer da luz minha mãe entoava, quase em surdina, uma canção que ela tirara de seu invento. Para ela, os flamingos eram eles que empurravam o sol para que o dia chegasse ao outro lado do mundo (p.47).

Os flamingos, comuns ao longo das zonas costeiras e lagoas pouco profundas das regiões tropicais, são aves graciosas, de voz poderosa e altura de quase um metro. Podem ser brancos ou rosados com penas pretas nas asas. Na América do Norte, atualmente, os flamingos são protegidos por lei, pois a procura por sua bela plumagem quase provocou a extinção da espécie. O flamingo-grande ou flamingorosa é uma das aves mais antigas do mundo. Tanto o grande quanto o "lesser" são encontrados em abundância no Quênia. O Parque Nacional do Lago Nakuru, localizado na região central da República do Quênia, é um fantástico santuário, com mais de um milhão de flamingos, frequentemente definido como o "maior espetáculo ornitológico da 
Terra". ${ }^{4}$ Ainda não se estabeleceu um padrão claro de migração dessas aves. Enquanto alguns indivíduos de uma mesma colônia se mantêm no local onde nasceram, outros viajam por vários milhares de quilômetros.

É essa possibilidade de opção e confiança na renovação dos dias; de liberdade - do partir e do voltar, ou, do não voltar - contidos na estória do flamingo, contada pela mãe, que vai ocupar o imaginário do menino e se renovar na idade adulta, diante da realidade de Tizangara. O pássaro é um símbolo metonímico de uma sociedade livre, na qual o homem é senhor de si e determina as suas ações. É, também, símbolo de esperança. Considerada ave "salva-vidas", "[n]o meio da noite, em plena tempestade, quando se perde noção da terra, é a presença e a voz dos flamingos que orienta os pescadores perdidos" (p.132). Em certa pescaria, o Velho Sulplício tinha sido salvo pelas aves. "Desde então, [...] fixara o canto dos bichos e regressava a essa memória sempre que se sentia perdido" (p.133). Assim, quando o flamingo se lançou num último voo e se extinguiu, "a noite se estreou naquela terra", conta a mãe. "Era o ponto final" (p.115).

Em Tizangara, matar os flamingos era uma prova de macheza, que o velho Sulplício reprovava. E com voz forte, passa para o filho, "inesquecíveis palavras":

O seu avô nos levava a mim e seu tio para caçarmos. [...]. De repente, seu avô batia as palmas e corria, aos berros para enxotar os bichos [...]. E meu tio se aprontando, no encoberto do tronco. De repente, o pau cortava o ar [...], se escutava o embatimento, as pernas da ave descobrindo súbitos novos joelhos e se abatendo como o fino arbusto perante o relâmpago [...]. Eu ficava especado a assistir àquela tristeza. Meu pai acorria e mandava: - Kufa mbalame! Era ordem de matar o pássaro. Nas mãos de meu irmão, o pau cumpria o mandato, o bicho se derradeirava. Aquele golpe se anichava em minha alma. O pássaro morria em mim. O pior, contudo, ainda estava por vir. À noite, eu era obrigado a comer aquela carne. Meu pai achava que me faltava dureza, prontidão de matar. Devia então comer aquele destroço. Para ser homem. Recusava-me [...]. E batia-me [...]. Eu me sentia frágil, perseguido por essa vergonha (p.187).

${ }^{4}$ Disponivel em www.girafamania.com.br. Acesso em 31 de agosto de 2008. 
Ao manifestar, de forma poética, seu constrangimento diante da crueldade com os pássaros, Mia Couto confere à arte o seu papel de continuadora "da Criação onde o espírito divino a abandonou" (STEINER, 1998, p. 34). “O verbo literário, simples medianeiro entre a natureza e o intérprete" vai promover a "revisão do mundo" (CANDIDO, 2006, p. 346). Dessa forma, como intérprete da natureza, Mia Couto vai reabrir a discussão de uma questão ambiental emergente: a extinção de espécies animais. Mas muito além do fático, do real, "a externalidade do ambientalismo complexo [...] é a natureza externalizada, as identidades desterritorializadas; o real negado e os saberes subjugados pela razão totalitária, o lógos unificador; a globalidade homogeneizante, a lei universalizante, a ecologia generalizada" (LEFF, 2002, p. 220).

Em junho de 2001, em discurso, durante a entrega do Prêmio Mário António, da Fundação Calouste Gulbenkian, Mia Couto lança, outra vez, seu "pássaro de papel". Nele, a razão a mais de sua ficção:

No verão de 1998, caminhando por uma praia do sul de Moçambique, encontrei, esvoante sobre a areia, uma pena de flamingo. Os pescadores locais me haviam dito que, outrora, por ali ninhavam bandos de flamingos. Fazia tempo, porém, eles não vinham. [...] $\mathrm{Na}$ tradição daquele lugar, os flamingos são os eternos anunciadores de esperança. Uma inexplicável angústia me assaltou - e se os pássaros não voltassem mais? $\mathrm{E}$ se todos os flamingos de todas as praias tivessem sido tragados por longinquas trevas? [...] Guardei em minha casa essa pena e a coloquei por cima do meu computador. Durante os dois anos em que escrevi este romance, aquela pluma me contemplou como se fosse uma fresta de céu por onde desfilavam os pássaros e suas secretas viagens [...]. É uma escrita que aspira ganhar sotaques do chão, fazer-se seiva vegetal e, de quando em quando, sonhar o voo da asa rubra. É uma resposta pouca perante os fazedores de guerra e construtores da miséria. Mas é aquela que sei e posso, aquela em que apostei a minha vida e o meu tempo de viver. [...] Muito obrigado por me ajudarem a acreditar que [...] os pescadores do meu país festejarão o regresso dos flamingos (COUTO, p. 223-225).

Hoje, em Moçambique, o Fórum Natureza em Perigo (FNP), associação nacional de cidadãos, criada em 1999, exerce a missão de 
conservação de sua biodiversidade. Entre seus projetos está o Clube Ornitológico de Moçambique, que incentiva a pesquisa sobre as aves do país. ${ }^{5}$

Em sua proposta para a construção do saber ambiental, Enrique Leff propõe a abertura do campo do conhecimento para a utopia, a diversidade, a outridade e o diálogo de saberes. Dessa forma, "Uma estória de amor" e $O$ último voo do flamingo apresentam-se como espaços de reflexão sobre o "ser na cultura dos diferentes contextos nos quais codifica e significa a natureza" (LEFF, 2002, p. 19) e abrem vias para a compreensão da complexidade ambiental. Como elos de uma mesma corrente, prendem por laços éticos e estéticos as bases para a construção de uma nova racionalidade ambiental.

\section{Referências bibliográficas}

BARTHES, Roland. Aula. Trad. Leyla Perrone-Moisés. São Paulo: Cultrix, 1989.

Bíblia Sagrada. Encyclopaedia Britannica Publishers. 1972.

CANDIDO, Antonio. Formação da literatura brasileira: momentos decisivos. 10.ed. Rio de Janeiro: Ouro sobre Azul, 2006.

COUTO, Mia. O último voo do flamingo. São Paulo: Companhia das Letras, 2005.

DIEGUES, Antonio Carlos. O mito moderno da natureza intocada. 3.ed.

São Paulo: Hucitec, Núcleo de apoio à pesquisa sobre populações humanas e áreas úmidas brasileiras, USP, 2000.

FANTINI, Marli. Guimarães Rosa: fronteiras, margens, passagens. São

Paulo: Ateliê Editorial, 2003.

LEFF, Enrique. Epistemologia ambiental.3.ed. São Paulo: Cortez, 2002.

LORENZ, Günter. Diálogo com Guimarães Rosa. In: João Guimarães Rosa: ficção completa. Rio de Janeiro: 1994. V.1.

5Disponivel em www.fnp.org.mz. Acesso: em primeiro de setembro de 2008. 
RAMOS, Maria Luiza. Interfaces: literatura mito inconsciente cognição. Belo Horizonte: Ed. UFMG, 2000.

ROSA, João Guimarães. Manuelzão e Miguilim. 9.ed. Rio de Janeiro: Nova Fronteira, 1984.

STEINER, Rudolf. Arte e estética segundo Goethe: Goethe como inaugurador de uma estética nova. 2. ed. São Paulo: Antroposófica, 1998.

TUNDISI, José Galizia. Água no século XXI: enfrentando a escassez. São Carlos: Rima, 2003. 